\title{
Multiband Planar Monopole Antenna for LTE MIMO Systems
}

\author{
Yuan Yao, Xing Wang, and Junsheng Yu \\ School of Electronic Engineering, Beijing University of Posts and Telecommunications, \\ Beijing 100876, China \\ Correspondence should be addressed to Yuan Yao, yaoy@bupt.edu.cn
}

Received 9 August 2011; Accepted 9 September 2011

Academic Editor: Li Yang

Copyright (c) 2012 Yuan Yao et al. This is an open access article distributed under the Creative Commons Attribution License, which permits unrestricted use, distribution, and reproduction in any medium, provided the original work is properly cited.

\begin{abstract}
A novel multiband-printed planar monopole antenna for LTE multi-input and multi-output (MIMO) application is proposed. A meandering microstrip line-loaded monopole antenna with multiband characteristic is presented. The proposed antenna provides five frequency bands for LTE application, covering $0.7,1.7,2.1,2.3$, and $2.5 \mathrm{GHz}$. In order to provide low mutual coupling and envelope correlation, two of the antennas are combined with orthogonal polarizations. The mutual coupling of the antenna is lower than $-13 \mathrm{~dB}$ across the operation bands. Both the simulated and measured results are shown to illustrate the performances of the proposed antenna.
\end{abstract}

\section{Introduction}

Nowadays, there are more and more interests in research on multi-input and multi-output (MIMO) systems in the wireless communication. Since it has the ability to increase the capacity of channel using the spatial properties of multipath, it is necessary to have a number of uncorrelated antennas at each end of the communication link. So it seems to be very essential to design adequate antenna due to use in MIMO systems. As revealed in many literatures [1-4], both of nonprinted MIMO antennas such as planar-inverted $\mathrm{F}$ antennas (PIFAs) and printed MIMO antennas are proposed. However, among the antennas which are used for MIMO application, printed antennas are more appropriate due to their low cost, easy fabrication, and their capability of easily being integrated to small terminal devices. Rapid developments in the wireless communication require novel antenna designs which can be used for multifunctional systems, which means that the antenna should have more than one frequency band. A tri-band E-shaped printed monopole antenna loaded with two U-shaped resonance paths suitable for MIMO systems for WLAN application, covering $2.4,5.4$, and $5.8 \mathrm{GHz}$, is reported in [5].

In this paper a novel multiband-printed planar monopole antenna for LTE MIMO application is presented. It can provide five frequency bands for LTE applications, covering
$746-787 \mathrm{MHz}, \quad 1710-1755 \mathrm{MHz}, \quad 2110-2155 \mathrm{MHz}, \quad 2305-$ $2400 \mathrm{MHz}$, and $2500-2690 \mathrm{MHz}$. This multiband characteristic is obtained by loading a meandering line to an ultrawideband planar monopole antenna. Two elements of such antennas are used for MIMO applications. The proposed structure obtains low mutual coupling and envelope correlation due to the orthogonal polarization.

\section{Antenna Structure and Mechanism}

As we know, printed planar monopole antennas have been widely used in wireless communication devices. They are very popular for volume-limited and wideband applications. The structure of the proposed multiband MIMO antenna is shown in Figure 1. This antenna is printed on an FR4 substrate with relative permittivity 4.4 and thickness of $1.6 \mathrm{~mm}$. The two identical antenna elements have the same structure and dimensions. The antenna has two layers, the top layer and the bottom layer. On the bottom layer there are the grounds with length $L_{g}$ and width $W_{g}$. On the top layer is the microstrip line-loaded monopole. The antenna is fed by a microstrip line with width $3 \mathrm{~mm}$ to match $50 \Omega$. The monopole is rectangular with width $W_{2}$ and length $L_{1}$ and $L_{2}$. The loaded microstirp line has width $W_{\text {strip }}$ and length of one path $L_{\text {strip. }}$. The two antenna elements are spaced 


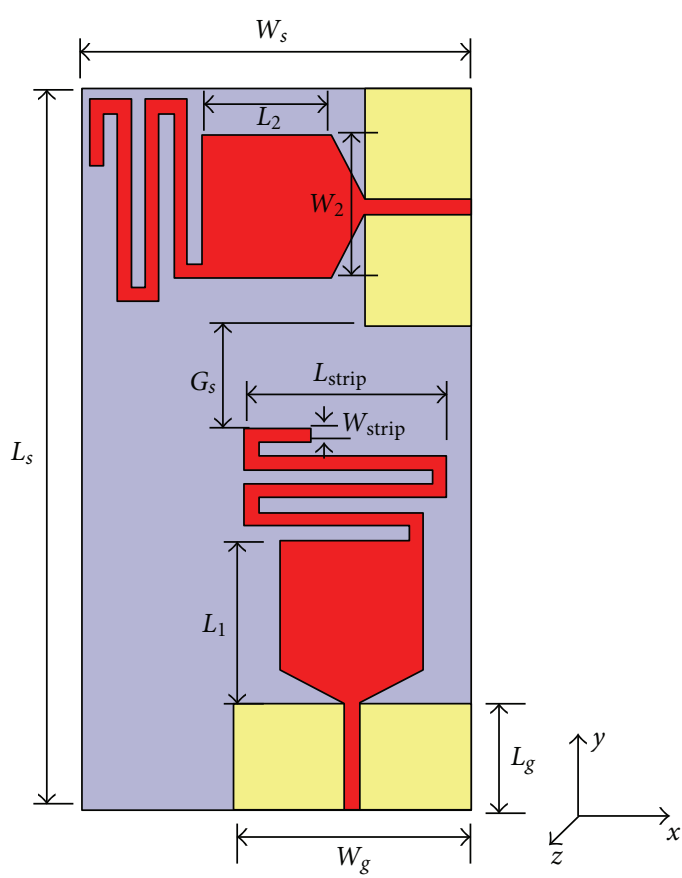

Figure 1: The geometry of the proposed antenna.

TABle 1: Antenna dimensions.

\begin{tabular}{lccccc}
\hline Dimension & $L_{s}$ & $W_{s}$ & $L_{g}$ & $W_{g}$ & $L_{1}$ \\
Size $(\mathrm{mm})$ & 153 & 83 & 22.7 & 50 & 34.8 \\
\hline Dimension & $L_{2}$ & $W_{2}$ & $L_{\text {strip }}$ & $W_{\text {strip }}$ & $G_{s}$ \\
Size $(\mathrm{mm})$ & 27.7 & 50 & 40 & 3 & 20 \\
\hline
\end{tabular}

with a gap $G_{s}$. The detailed antenna dimensions are listed in Table 1.

In order to achieve a compact multiband antenna, a novel structure is proposed in this paper. The multiband characteristic is obtained by loading a meandering microstrip line to an ultra-wideband monopole element. Figure 2 shows the monopole antenna without microstrip line loaded and the return loss of this antenna. It can be seen that this kind of monopole antenna has ultra-wideband characteristics covering from $1700 \mathrm{MHz}$ to $2900 \mathrm{MHz}$ frequency band. However, only the monopole antenna cannot cover the LTE $700 \mathrm{MHz}$ band. Then a meandering microstrip line is loaded. As shown in Figure 3 the current distribution at $750 \mathrm{MHz}$ reveals the resonance at LTE $700 \mathrm{MHz}$ band.

In addition to the traditional antenna parameters, such as gain, radiation pattern, and reflection coefficients, new parameters and aspects have to be included in the design for MIMO systems. Mutual coupling between antenna elements is a key factor to achieve high antenna performance in the MIMO antenna configuration. For a low mutual coupling, antennas must be far away from each other. But the space for the internal antenna is not enough to obtain low correlation and mutual coupling. In this paper we present a structure for the MIMO antenna elements, in which the identical two antenna elements are orthogonally placed. Then the two antenna elements have orthogonal polarization which

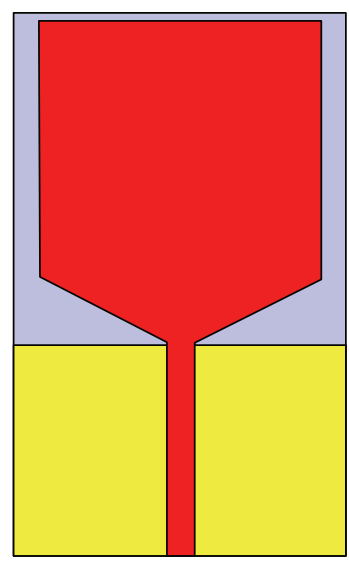

(a) Structure

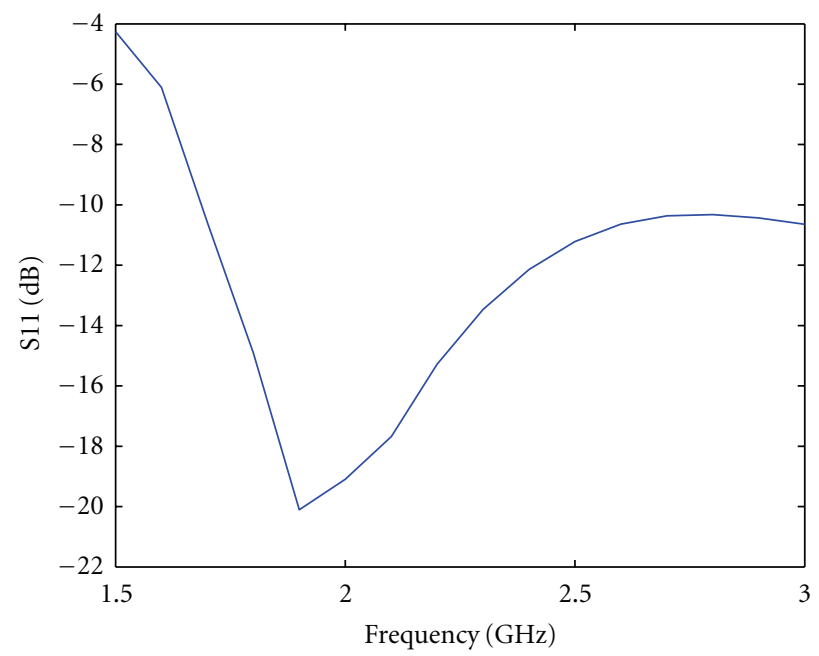

(b) S11 results

FIGURE 2: The structure and return loss of the ultra-wideband monopole antenna.

can reduce the mutual coupling between the two antennas. Figure 4 shows the simulated $3 \mathrm{D}$ radiation patterns of the two antenna elements. It can be seen that the two antenna elements have orthogonal polarizations.

\section{Simulation and Measurement Results}

To validate the above analysis, the proposed structure is simulated in HFSS and measured in an anechoic chamber. A prototype of the proposed antenna as shown in Figure 5 was fabricated and tested, and the detailed dimensions can be found in Table 1. Figure 6 shows the simulated and measured return loss, which agree well. The measured $-10 \mathrm{~dB}$ return loss bandwidths are $745-790 \mathrm{MHz}$ and $1700-3000 \mathrm{MHz}$, which cover the whole LTE bands. The mutual coupling between the two ports is less than $-13 \mathrm{~dB}$ across the common bandwidth, as shown in Figure 7.

Figures 8 and 9 show the radiation patterns of the antenna 1 and the antenna 2 at $760 \mathrm{MHz}, 1750 \mathrm{MHz}, 2150 \mathrm{MHz}$, 


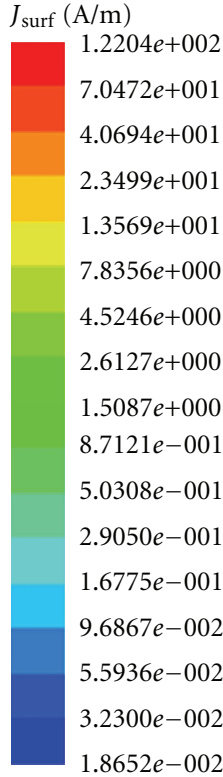

Figure 3: Current distribution at $750 \mathrm{MHz}$.
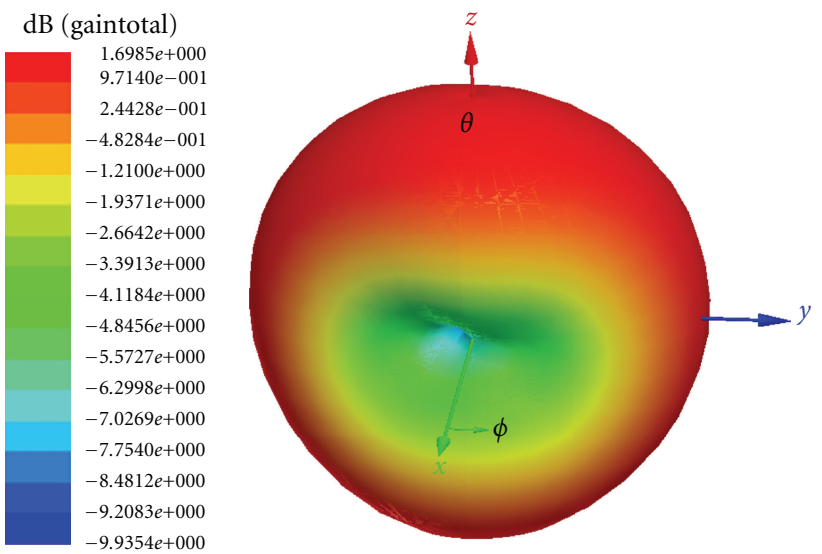

(a)
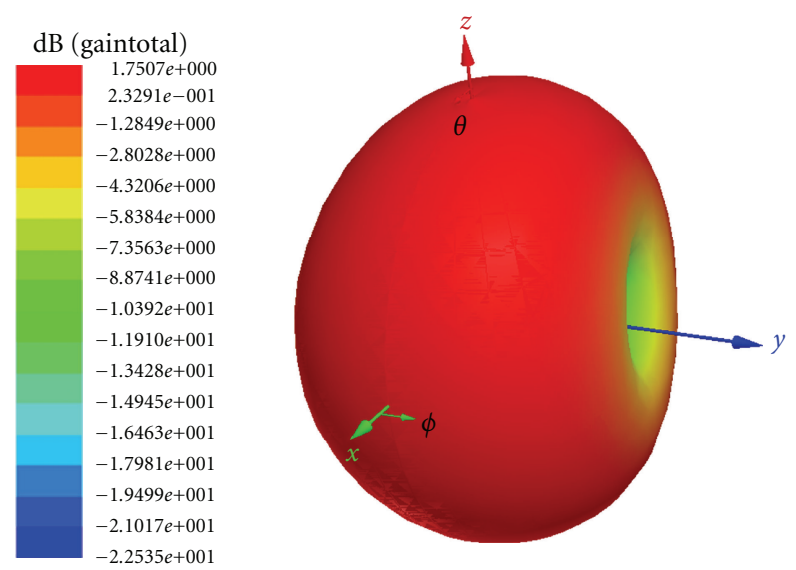

(b)

FIGURE 4: 3D radiation patterns of the two antenna elements.

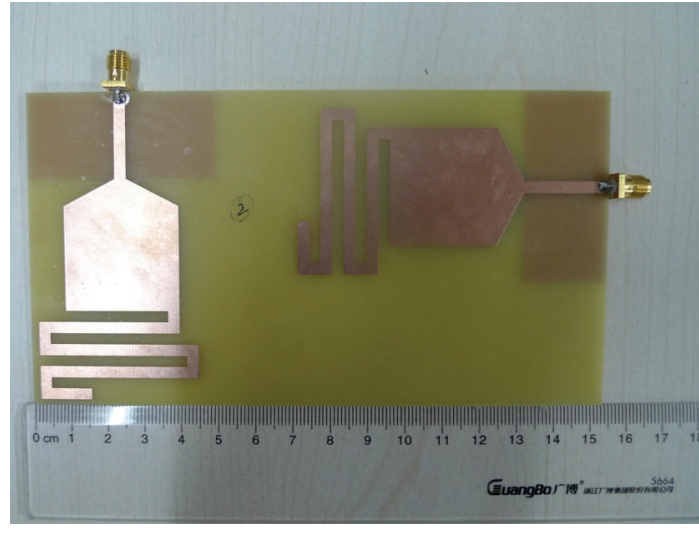

FIgURE 5: Photograph of the fabricated antenna.

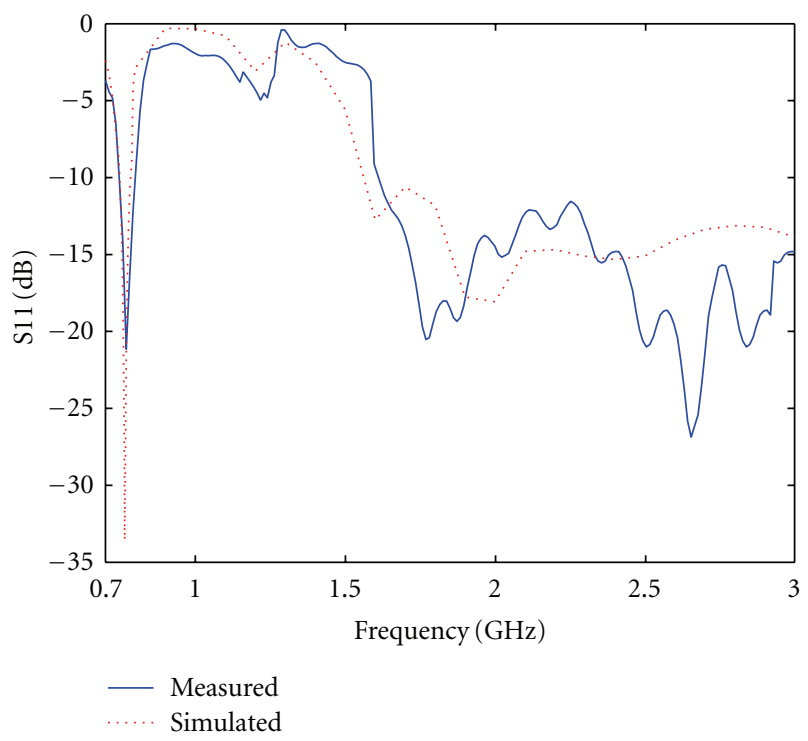

FIGURE 6: Simulated and measured S11 of the proposed antenna.

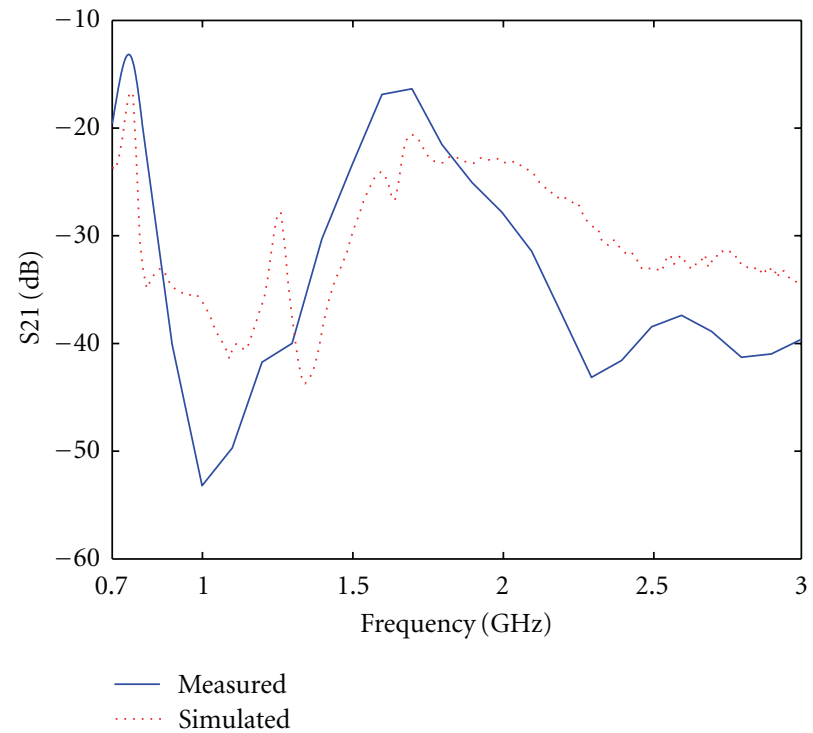

FIgURE 7: Simulated and measured S21 of the proposed antenna. 


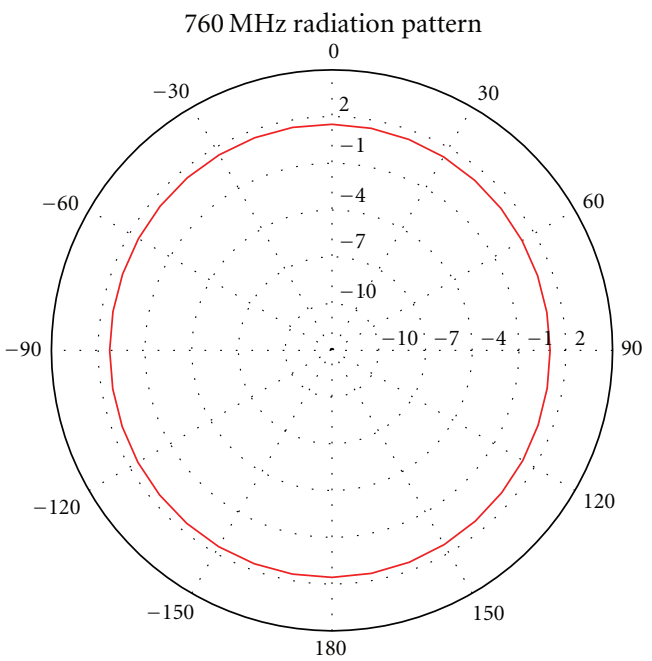

(a) $760 \mathrm{MHz}$

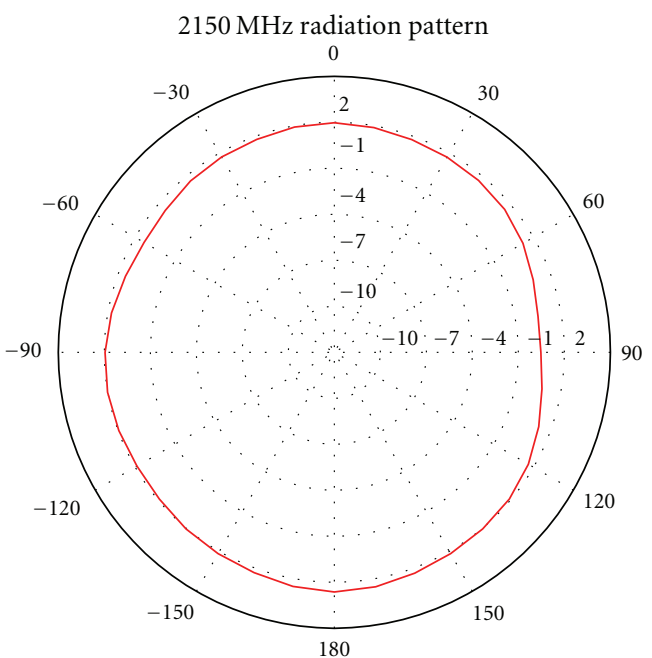

(c) $2150 \mathrm{MHz}$

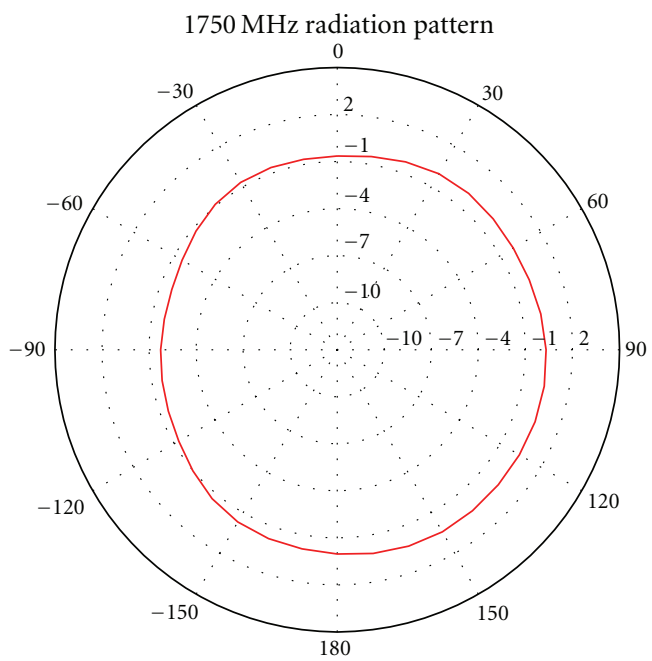

(b) $1750 \mathrm{MHz}$

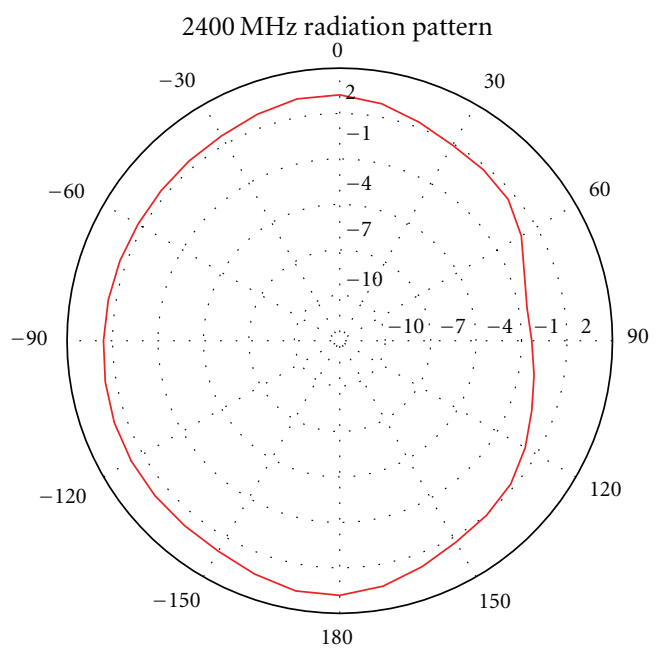

(d) $2400 \mathrm{MHz}$

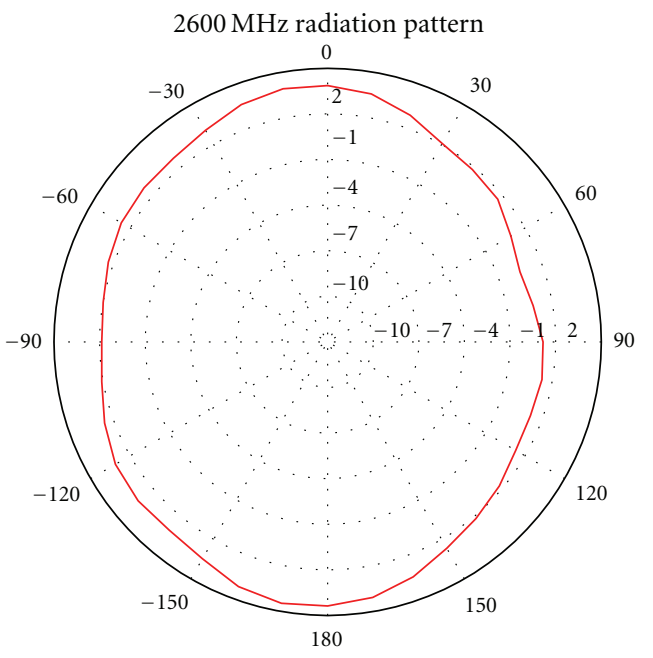

(e) $2600 \mathrm{MHz}$

FIgURE 8: Radiation patterns of antenna 1 in $x-z$ plane. 


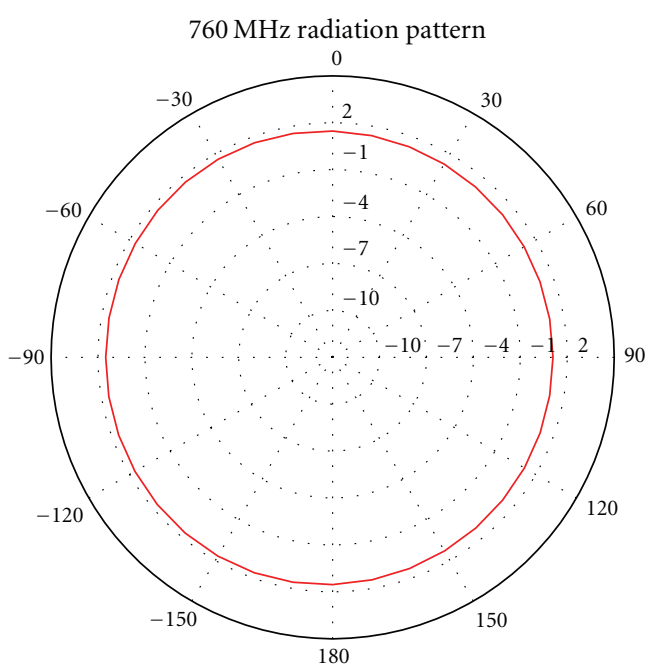

(a) $760 \mathrm{MHz}$

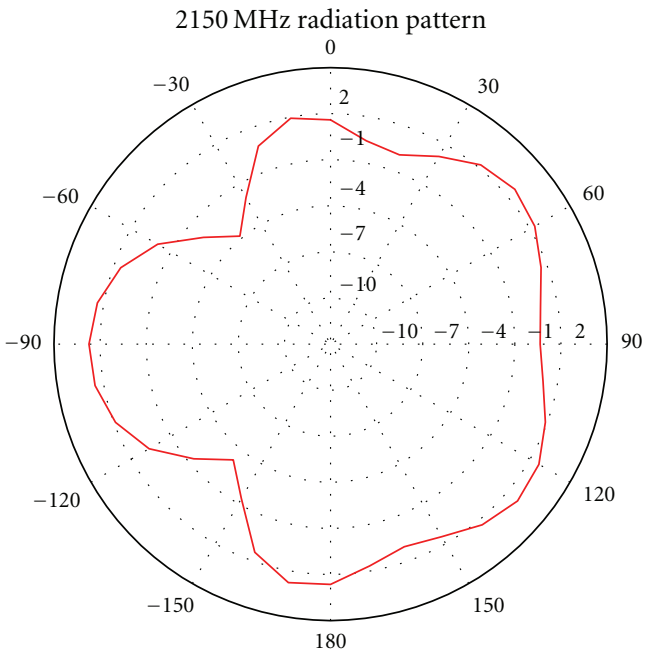

(c) $2150 \mathrm{MHz}$

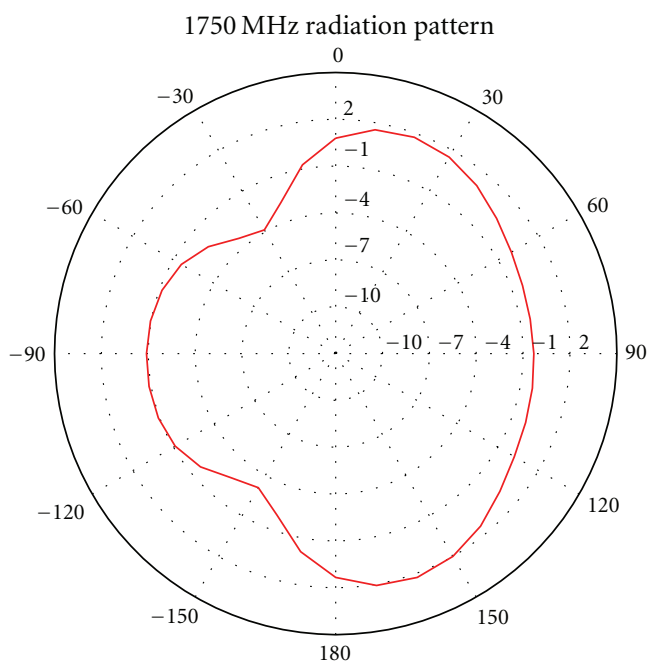

(b) $1750 \mathrm{MHz}$

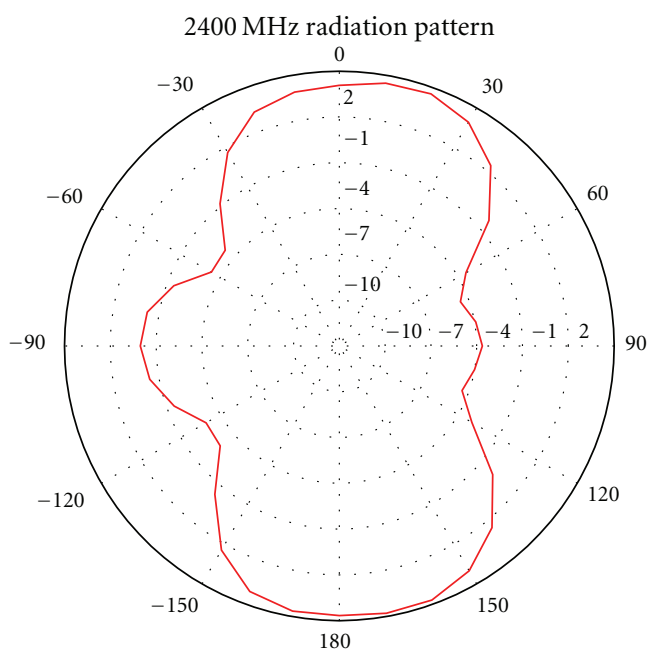

(d) $2400 \mathrm{MHz}$

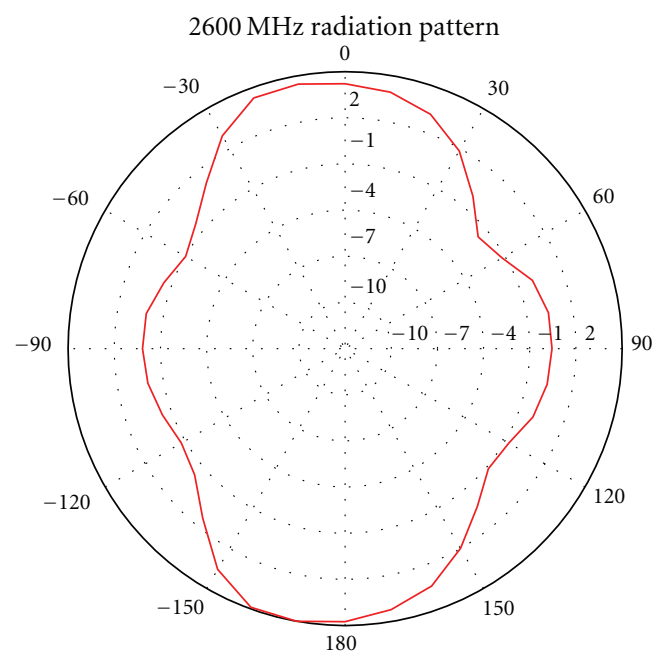

(e) $2600 \mathrm{MHz}$

FIgURE 9: Radiation patterns of antenna 2 in $y-z$ plane. 


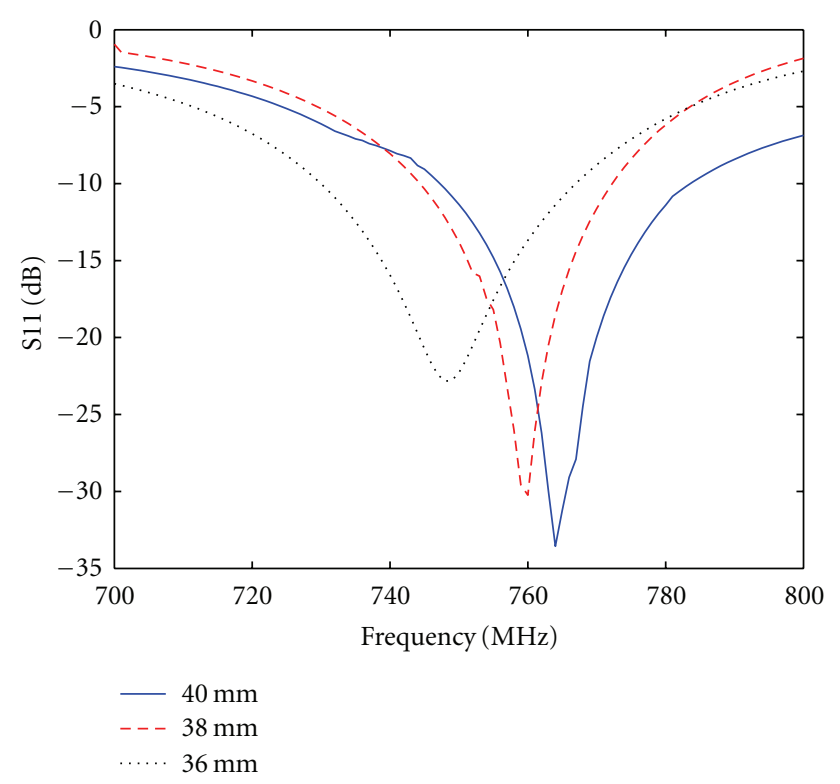

FIGURE 10: S11 of the antenna with different $L_{\text {strip }}$.

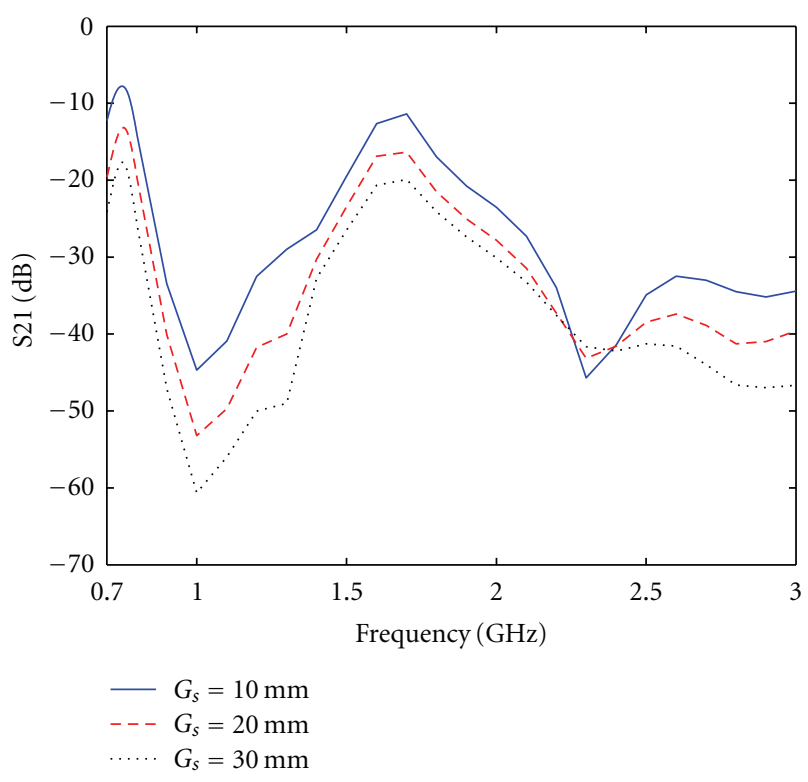

Figure 11: S21 of the antenna with different $G_{s}$.

$2400 \mathrm{MHz}$, and $2600 \mathrm{MHz}$. The antenna 1 has an omnidirectional vertically polarized pattern in $x-z$ plane and the antenna 2 generates horizontally polarized radiation in $y$ $z$ plane. The omnidirectional patterns can enhance and increase the channel capacity [6]. Thus the proposed antenna is more attractive for MIMO application.

\section{Parameter Study}

For the purpose of optimized performance, parametric studies of the dimensions of the antenna structure are carried out. First, we analyze the length of the meandering microstrip line. As presented in Figure 10, the resonant frequency at LTE 700 of the antenna is changeable. The resonant frequency goes up when the length is longer and goes down when the length is smaller.

The isolation between two polarizations will be affected by the dimension of spacing $G_{s}$. In principle, the larger the spacing is, the lower of the mutual coupling will be. As shown in Figure 11, the spacing is changed from $10 \mathrm{~mm}$ to $30 \mathrm{~mm}$ and the mutual coupling is from below $-9 \mathrm{~dB}$ to below $-19 \mathrm{~dB}$.

\section{Conclusion}

In this paper a design of multiband planar monopole antenna for LTE MIMO system has been proposed and implemented. Simulated and measured results showed that the antenna can cover five LTE frequency bands and has high isolation. The proposed antenna will provide better propagation channel and enhance the capacity of MIMO system.

\section{Acknowledgment}

This work is supported by the Fundamental Research Funds for the Central Universities.

\section{References}

[1] A. R. Mallahzadeh, S. F. Seyyedrezaei, N. Ghahvehchian, S. Mohammad Ali Nezhad, and S. Mallahzadeh, "Tri-band printed monopole antenna for WLAN and WiMAX MIMO systems," in Proceedings of the 5th European Conference on Antennas and Propagation (EUCAP '11), pp. 548-551, April 2011.

[2] H. T. Chattha, Y. Huang, X. Zhu, and Y. Lu, "Dual-feed PIFA diversity antenna for wireless applications," Electronics Letters, vol. 46, no. 3, pp. 189-190, 2010.

[3] Q. Luo, J. R. Pereira, and H. M. Salgado, "Reconfigurable dualband C-shaped monopole antenna array with high isolation," Electronics Letters, vol. 46, no. 13, pp. 888-889, 2010.

[4] Y. Li, Z. Zhang, W. Chen, Z. Feng, and M. F. Iskander, "A dualpolarization slot antenna using a compact CPW feeding structure," IEEE Antennas and Wireless Propagation Letters, vol. 9, pp. 191-194, 2010.

[5] S. M. Ali Nezhad and H. R. Hassani, "A novel triband Eshaped printed monopole antenna for MIMO application," IEEE Antennas and Wireless Propagation Letters, vol. 9, pp. 576$579,2010$.

[6] R. G. Vaughan and J. B. Andersen, "Antenna diversity in mobile communication," IEEE Transactions on Vehicular Technology, vol. 36, no. 4, pp. 149-172, 1987. 

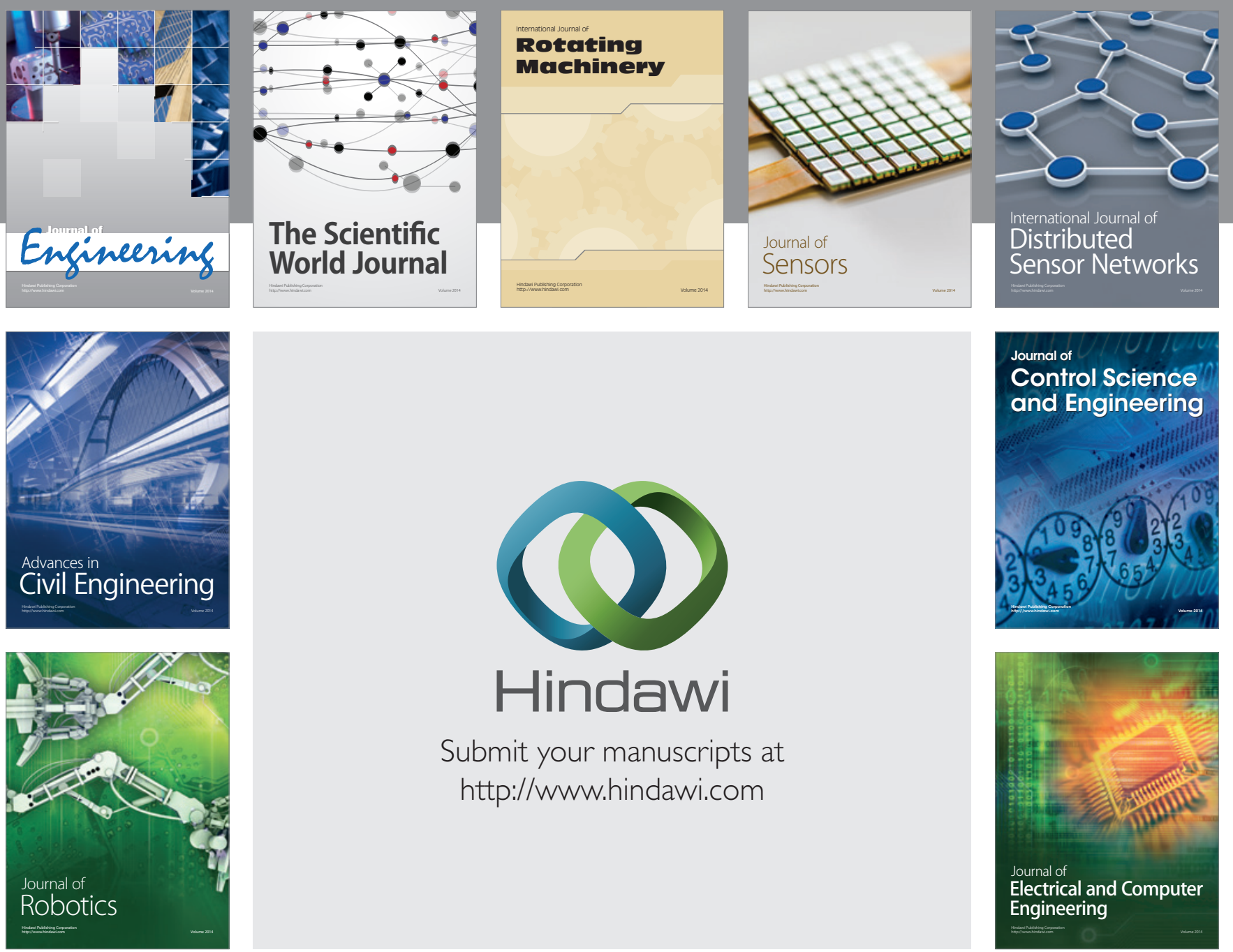

Submit your manuscripts at

http://www.hindawi.com
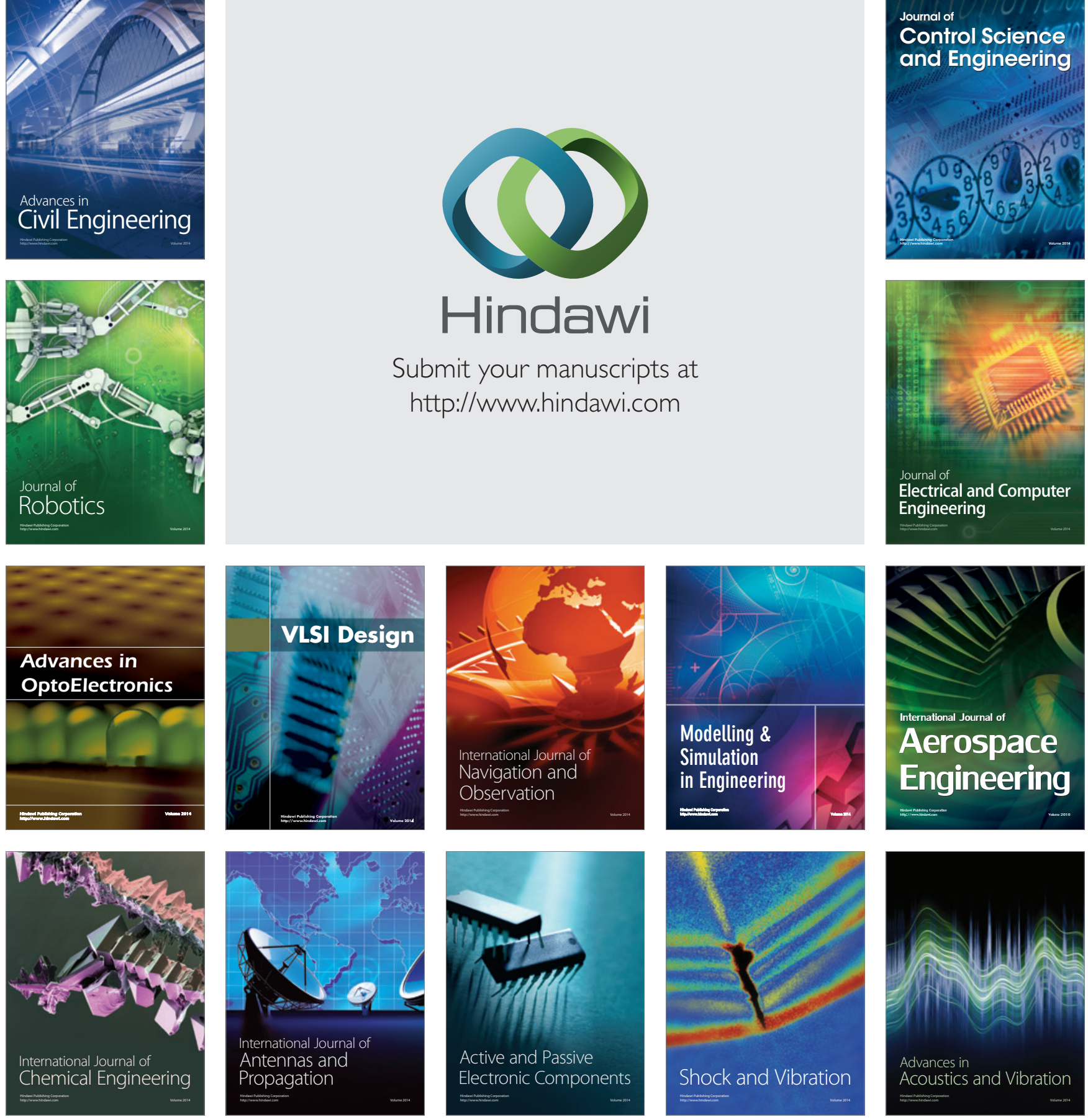